\title{
Density, group composition and encounter rates of humpback whales (Megaptera novaeangliae) in the eastern Comoros Archipelago (C2)
}

\author{
Peter J. ERsts*, Jeremy KiszKA ${ }^{+, \#,}$, Michel Vély $\sim$ And Howard C. Rosenbaum ${ }^{++, *}$ \\ Contacte-mail: ersts@amnh.org
}

\begin{abstract}
The Comoros Archipelago is an assemblage of oceanic islands, banks and offshore reef systems that longitudinally span the northern Mozambique Channel. The greater Comoros Archipelago has been designated by the IWC as Wintering sub-Region C2 for humpback whales and is currently considered data deficient. Since 1997, annual marine mammal surveys of varying length and objective have been carried out in the waters surrounding Mayotte, the eastern most island in the Comoros Archipelago. The humpback whales component of these surveys focused effort in and around the lagoon surrounding Mayotte. While it is expected that humpback whales can found throughout Comoros Archipelago it still remains unknown as to what degree humpback whales utilise specific banks and offshore reef systems within this area. Surveys conducted in 2002 and 2003 included passing mode and closing mode components intended to examine the density, group composition and encounter rates of humpback whales in an offshore reef complex and a bank adjacent to the lagoon surround Mayotte. The densities of humpback whales, out to one nautical mile from the surveyed transects, ranged from 0.027 to 0.618 whales/n.mile ${ }^{2}$ across three study sites. Females with calves were the most frequently encountered group type. Encounter rates ranged from 0.98 to 2.36 groups per hour of search effort. These results, while exploratory in nature, indicate that the eastern region of the Comoros may be an important area for humpback whales during the late austral winter months and that additional, more intensive systematic research is warranted.
\end{abstract}

KEYWORDS: HUMPBACK WHALE; BREEDING GROUNDS; CONSERVATION; SURVEY-VESSEL; SOUTHERN HEMISPHERE

\section{INTRODUCTION}

During the austral winter, humpback whales (Megaptera novaeangliae) undertake an annual migration from the cold waters of Antarctic feeding grounds to the warm waters of low-latitude wintering regions where breeding and calving take place. The International Whaling Commission (IWC) recognises seven major low-latitude wintering regions (AG) for management of Southern Hemisphere humpback whale populations (IWC, 2000; 2004). The southwestern Indian Ocean has been designated Wintering Region $\mathrm{C}$ and is currently further partitioned into three smaller units; Wintering sub-Region $\mathrm{C} 1, \mathrm{C} 2$, and $\mathrm{C} 3$. These sub-regions largely correspond to the termini of three migratory streams postulated to exist within the southwestern Indian Ocean (Best et al., 1998). One of the proposed migratory streams is thought to carry humpback whales northward through the centre of the Mozambique Channel to the Comoros Archipelago; designated by the IWC as Wintering subRegion C2. Despite their close proximities, aggregations of whales in the Comoros Archipelago are differentiated from aggregations found along the eastern coast of South Africa and Mozambique (C1) (Findlay and Best, 1996; Findlay et al., 1994) and from aggregations found along eastern and southern coast of Madagascar (C3) (Best et al., 1998; Best et al., 1996; Rosenbaum et al., 1997); however recent evidence has shown that individual humpback whales utilise both $\mathrm{C} 1$ and $\mathrm{C} 2$ (Ersts et al., 2011).

The Comoros Archipelago is an assemblage of oceanic islands, banks and offshore reef systems that longitudinally span the northern Mozambique Channel between Madagascar and Mozambique. Elsewhere in the world, humpback whales are frequently observed in near-shore waters of low-latitude island chains where movement among close, adjacent islands and banks has been well documented through photographic analysis (Baker and Herman, 1981; Baker et al., 1986; Balcomb and Nichols, 1982; Calambokidis et al., 2001; Cerchio et al., 1998; Darling and Morowitz, 1986; Garrigue et al., 2002; Garrigue et al., 2000; Mattila and Clapham, 1989; Mattila et al., 1989; Mattila et al., 1994; Urban and Aguayo, 1987; Whitehead and Moore, 1982). Satellite telemetry data has also demonstrated that humpback whales show a strong preference for shallower waters than for deeper inter-island channels and that animals can quickly move through an entire archipelago (Mate et al., 1998). To date, limited systematic effort has been applied toward understanding humpback whales in Wintering subRegion C2 (Rosenbaum et al., 2001) and little published data are available (Kiszka et al., 2007). While it is expected that humpback whales can found throughout $\mathrm{C} 2$, it still remains unknown as to what degree humpback whales utilise specific banks and offshore reef systems within this area.

Récif du Geyser (Geyser Reef) and Banc de la Zélée (Zélée Bank) form an isolated offshore reef complex on the eastern edge of the Comoros Archipelago. This complex along with the Banc de l'Iris (Iris Bank), a bank of similar size and structure adjacent to the island of Mayotte, possess environmental conditions that have been broadly described as those sought by humpback whales during their stay in the low-latitude wintering regions (Balcomb and Nichols, 1982;

* Center for Biodiversity and Conservation, American Museum of Natural History, Central Park West at 79th Street, New York, New York, 10024 USA.

+ Observatoire des Mammifères Marins. Office National de la Chasse et de la Faune Sauvage and Direction de l'Agriculture et de la Forêt. BP 103. F-97600 Mamoudzou, Mayotte (France).

* LIENSS (Littoral, Environnement et Sociétés). UMR 6250 CNRS-Université de La Rochelle. 2, rue Olympe de Gouges. 17000 La Rochelle, France.

`Direction de l'Environnement et du Développement Durable. Conseil Général de Mayotte. BP 101, 97600 Mayotte (France).

Association MEGAPTERA, 23, rue Alexandre Dumas, 75011 Paris, France [Current address: Route Royale, Tamarin, Mauritius].

${ }^{++}$Wildlife Conservation Society, Ocean Giants Program, 2300 Southern Blvd., Bronx, NY 10460-1099, USA. 
Dawbin, 1966; Ersts and Rosenbaum, 2003; Smultea, 1994; Whitehead and Moore, 1982). However, due to the relative inaccessibility of the Geyser-Zélée Complex, the presence of humpback whales and other marine mammals has previously only been known from a few anecdotal reports by fisherman and charter boat captains.

Since 1997, annual marine mammal surveys of varying lengths and objectives have been carried out in the waters surrounding Mayotte. These surveys focused their effort in and around the lagoon surrounding Mayotte. Surveys conducted in 2002 and 2003 included an exploratory component intended to examine the density and group composition of humpback whales and other marine mammals utilising the Geyser-Zélée Complex. This paper presents the results from these exploratory surveys along with a comparison of sighting data collected during the same time period on Iris Bank. Wintering sub-Region C2 is particularly data-deficient for humpback whales (Rosenbaum et al., 2001) and these results, while exploratory in nature, represent much needed data to help describe this region and guide future research initiatives.

\section{METHODS}

\section{Study area}

Mayotte $\left(12^{\circ} 50^{\prime} \mathrm{S}, 4^{\circ} 10^{\prime} \mathrm{E}\right)$, a territorial collectivity of France, is a small island in the northern Mozambique

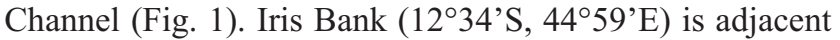
to the northern extent of the 437 n.mile ${ }^{2}$ lagoon surrounding Mayotte (Fig. 2). Iris Bank covers an area of approximately 65 n.mile ${ }^{2}$ with a mean depth of $30 \mathrm{~m}(\max 80 \mathrm{~m})$.

Geyser Reef and Zélée Bank (12 $\left.24^{\prime} \mathrm{S}, 46^{\circ} 25^{\prime} \mathrm{E}\right)$, form an isolated complex 80 n.mile northeast of the island of Mayotte (Fig. 3). This complex sits atop what is presumed to be a seamount of volcanic origin (Quod et al., 2000; UNEP and IUCN, 1988), and is composed of two distinct areas separated by a 4.5 n.mile wide channel that exceeds $600 \mathrm{~m}$ in depth.

Geyser Reef is approximately 120 n.mile ${ }^{2}$ in area while Zélée Bank is smaller, covering approximately 70 n.mile 2 . Depths on this complex range from $1 \mathrm{~m}$ near the reef crest to $40 \mathrm{~m}$ in the interior regions. The edge of the complex is characterised by near vertical walls that rapidly drop to depths of over $1,000 \mathrm{~m}$ within as little as $500 \mathrm{~m}$ of their shallowest points. The complex remains completely submerged at low tide, with the exception of a partially emergent western rim of the Geyser Reef.

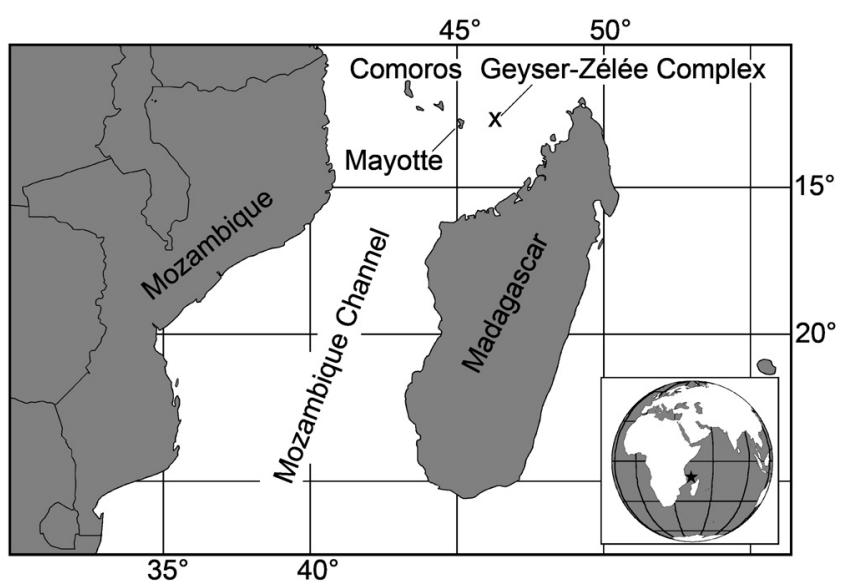

Fig. 1. Mayotte and the Geyser-Zélée Complex are situated on the eastern edge of the Comoros Archipelago, between Madagascar and Mozambique.

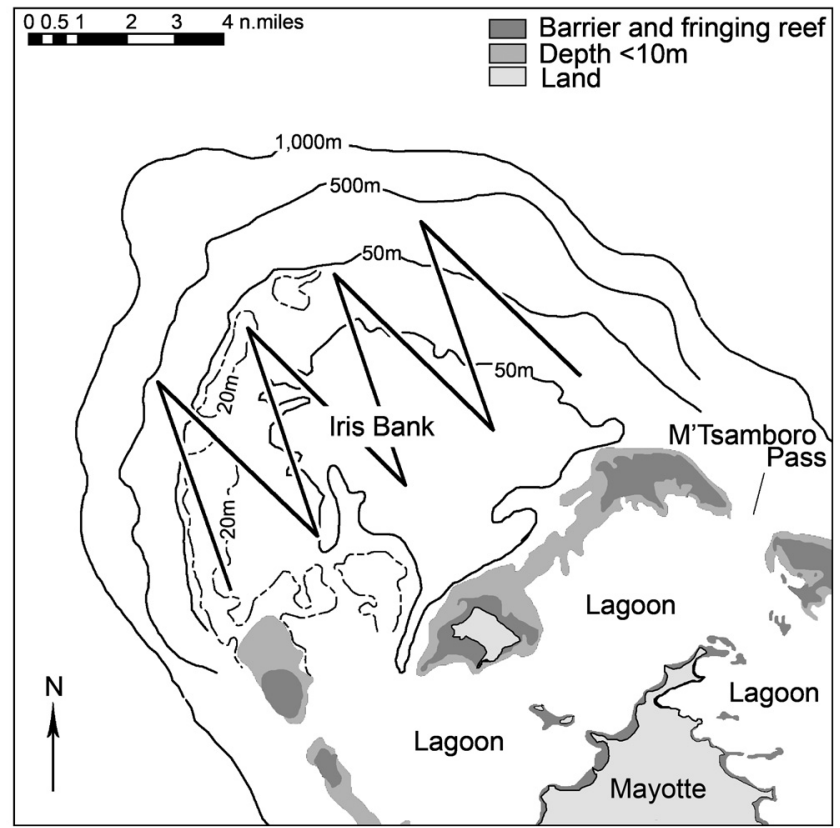

Fig. 2. Iris Bank.

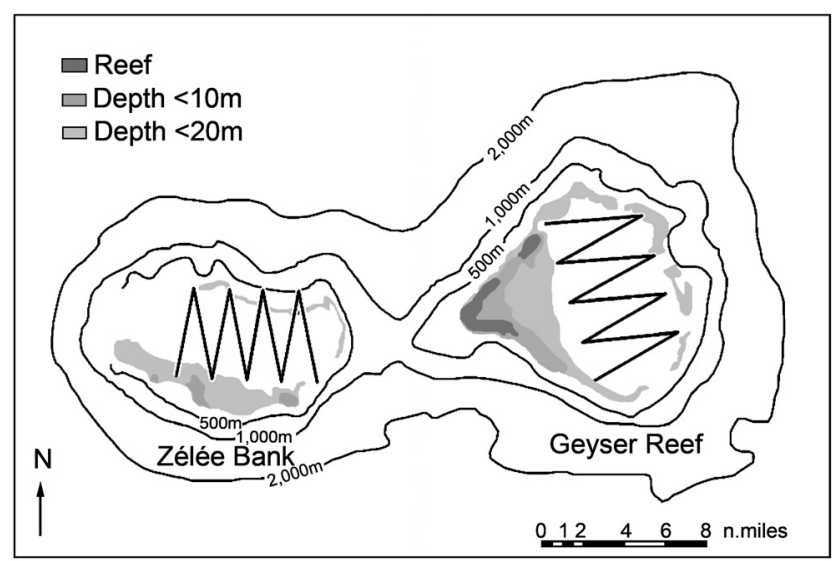

Fig. 3. Geyser-Zélée Complex.

\section{Surveys}

The initial survey of the Geyser-Zélée Complex was conducted in September 2002. When an opportunity occurred to return to the Geyser-Zélée Complex in October of 2003, the 2002 surveys were replicated for reason of comparability even though alternative survey designs were proposed after the 2002 experience.

Closing mode surveys for humpback whales were conducted in the waters surrounding Mayotte during the days and weeks immediately preceding and following the surveys of the Geyser-Zélée Complex. Tables 1 and 2 summarise survey effort applied during 2002 and 2003. As indicated in Table 1, survey objectives of 2002 included applying closing mode effort on Iris Bank as well as in the interior of the lagoon surrounding Mayotte. Data collected in the interior of the lagoon in 2002, however, are not reported here nor are they included in this analysis; only sighting data collected on Iris Bank were used for this analysis.

\section{Passing mode}

Line transect distance sampling methods (Buckland et al., 2001) were applied during surveys in the interior of Geyser Reef, Zélée Bank and Iris Bank (Figs 2 and 3) to determine 
Table 1

Summary of surveys conducted in 2002 and 2003

\begin{tabular}{|c|c|c|c|}
\hline Start date & End date & Location & Survey methods \\
\hline $27 / 08 / 02$ & 08/09/02 & $\begin{array}{l}\text { Lagoon surrounding } \\
\text { Mayotte* + Iris Bank }\end{array}$ & Closing mode only \\
\hline 09/09/02 & $14 / 09 / 02$ & $\begin{array}{l}\text { Geyser Reef }+ \\
\text { Zélée Bank }\end{array}$ & $\begin{array}{l}\text { Passing mode }+ \\
\text { Closing mode }\end{array}$ \\
\hline $15 / 09 / 02$ & $25 / 09 / 02$ & $\begin{array}{l}\text { Lagoon surrounding } \\
\text { Mayotte* + Iris Bank }\end{array}$ & Closing mode only \\
\hline $23 / 09 / 03$ & $01 / 10 / 03$ & Iris Bank & Closing mode only \\
\hline $05 / 10 / 03$ & $08 / 10 / 03$ & $\begin{array}{c}\text { Geyser Reef + } \\
\text { Zélée Bank }\end{array}$ & $\begin{array}{l}\text { Passing mode }+ \\
\text { Closing mode }\end{array}$ \\
\hline $09 / 10 / 03$ & $10 / 10 / 03$ & Iris Bank & Passing mode only \\
\hline $11 / 10 / 03$ & $16 / 10 / 03$ & Iris Bank & Closing mode only \\
\hline
\end{tabular}

*Data collected in the interior of the lagoon in 2002 are not reported here nor included in this analysis.

diversity and density of marine mammals. Pre-determined saw-tooth transects were uploaded to the navigational computer aboard the survey vessel, a $17.5 \mathrm{~m}$ catamaran chartered out of Mayotte. Transects were completed at eight knots with all aspects of navigation along the transects being controlled by the navigational computer (i.e. auto-pilot) aboard the survey vessel. A transect was composed of eight, 4.5 n.mile long legs with 2 n.miles between the apex of each saw-tooth. The same design was used on each of the three locations, although the orientation of each transect was different in order to maximise coverage.

Observations for marine mammals were carried out by two teams of four observers from the roof of the cabin, approximately $4.5 \mathrm{~m}$ above the water surface. Each team actively observed for four legs or approximately two hours at a time. When not on watch, team members remained below decks to minimise fatigue and potential observational bias. Each team consisted of a starboard and port side primary observer and data collector. The starboard and port observers worked independently observing in an arc from the trackline to perpendicular with the trackline on their respective side. Observers searched by naked eye and with binoculars. Starboard and port side teams were allowed to communicate with one another when a sighting was recorded near the trackline or at the apex of a saw-tooth in an attempt to minimise duplicate observations. The survey vessel did not deviate from the pre-determined transect at any time to attempt photographic identification or genetic sampling.
Data collectors recorded time (hour, minutes, seconds), estimates of group size ( $\min , \max$, best), cue (i.e. blow, breach), bearing and estimated distance to each sighting and geographic position at the time of initial detection. Where species determination was not possible, sightings were simply recorded as 'whale-like' or 'dolphin-like'.

Perpendicular distance estimates were calculated using a method based on spherical geometry as outlined in Ersts et al. (2008). This spherical method involves finding the intersection between two great-circles and requires the geographic location of the survey platform, a detection or radial distance, and the bearing to the sighting at the initial time of detection. This method was chosen because the configuration of the cabin roof did not allow for the use of angle boards. Bearings to sightings were obtained with handheld nautical sighting compasses. Bearings were recorded to the nearest degree and post-corrected to account for magnetic declination. The most experienced member of the observation team estimated the distance from the survey platform to the sighting at the time of initial detection. When possible, photographs were taken of each sighting; however, photographic techniques for estimating distance were not used in this analysis. Positional data were collected using either a hand-held Garmin eTrex Venture or Garmin Geko 201. Positional data were recorded in decimal degrees and stored with six or more significant digits so as not to introduce additional inaccuracies.

\section{Closing mode}

A closing mode methodology was employed in which the survey vessel would leave a previously determined search track in order to close on the group of whales or dolphins. The survey vessel would return to the search track once the group of whales or dolphins had been completely sampled or the maximum time limit (90 minutes) was reached. Maximum time limits were conservatively imposed to minimise any short-term alterations to behaviour or movement of the animals. Search tracks were designed to maximise spatial coverage but were not rigidly defined or followed. Consequently, only group size estimates from the closing mode data were used in the subsequent analyses of distribution and density.

When a group of marine mammals was encountered, the initial and last positions of the group were recorded in addition to descriptive attributes and photographs of tail flukes and dorsal fin features. Humpback whales were the

Table 2

Summary of closing mode effort, identified individuals, and encounter rates.

\begin{tabular}{|c|c|c|c|c|}
\hline & \multicolumn{2}{|c|}{ Geyser-Zélée Complex } & \multicolumn{2}{|c|}{ Iris Bank } \\
\hline & 2002 & 2003 & 2002 & 2003 \\
\hline Searching effort (hours)* & 7.20 & 5.69 & 19.17 & 17.33 \\
\hline Total closing mode effort (hours) ${ }^{* *}$ & 19.28 & 13.71 & 29.90 & 30.45 \\
\hline Groups & 17 & 9 & 13 & 17 \\
\hline Identified individuals (flukes/ dorsal) & $7 / 19$ & $6 / 14$ & $9 / 16$ & $4 / 27$ \\
\hline Dorsal only & 13 & 9 & 7 & 23 \\
\hline Flukes only & 1 & 1 & - & - \\
\hline Dorsal and flukes & 6 & 5 & 9 & 4 \\
\hline Groups/hour (searching effort) & 2.36 & 1.58 & 0.68 & 0.98 \\
\hline Identified individuals/hour (searching effort) & $0.97 / 2.64$ & $1.05 / 2.46$ & $0.47 / 0.83$ & $0.23 / 1.56$ \\
\hline Groups/hour (total effort) & 0.88 & 0.66 & 0.43 & 0.56 \\
\hline Identified individuals/hour (total effort) & $0.36 / 0.99$ & $0.44 / 1.02$ & $0.30 / 0.54$ & $0.31 / 0.87$ \\
\hline
\end{tabular}

*Searching effort refers to time spent actively searching for cetaceans. **Total closing mode effort includes time spent actively searching and sampling cetaceans, acoustic watches, acoustic recording, processing samples etc., but not time spent in transit. 
primary focus of these surveys, thus behavioural information was not collected for other cetacean species and photographic data of other species were only collected for species confirmation. Groups of humpback whales were classified into one of seven classes (mother-calf pairs, mother-calf-escort, pairs, competitive groups, noncompetitive, singers and singletons), based on observed attributes or behavioural characteristics previously described for this species (Baker and Herman, 1984; Clapham et al., 1992; Tyack and Whitehead, 1983). Acoustic watches were not systematically undertaken to search for singing whales. When solitary humpback whales with extended $(>15$ minutes) but regular dive intervals were encountered they were checked for singing periodically throughout the encounter when possible and the presence or absence of other humpback whales within sight of the survey vessel was also noted.

Humpback whales were photographed using a Nikon D1 digital camera fitted with an $80-200 \mathrm{~mm} 2.8 \mathrm{f}$ lens. Individual humpback whales were identified using photographs of the ventral side of their tail flukes (Katona and Whitehead, 1981), dorsal fins (Blackmer et al., 2000) and other natural markings.

\section{Density calculation}

Group densities were calculated with the same basic equation used in similar surveys throughout the West Indies (Mattila and Clapham, 1989; Mattila et al., 1994):

$$
\text { Density }=\frac{N_{W}}{(D \times 2 \times W)}
$$

where $N_{W}$ is the number of sightings up to $W$ n.miles from the track line and $D$ is the length of the trackline in nautical miles. Due to the exploratory nature of these surveys and the limitations of the survey vessel, detection functions were not fit to the observations and no attempt was made to correct for biases associated with weather, detection distance estimates, or observer experience. Whale density was calculated by multiplying the group density by the average group size determined from encounters made during closing mode surveys. This method for calculating density makes the assumption that group types encountered during closing mode surveys are representative of the group types observed during passing mode surveys. For added interpretability, passing mode data and their subsequent analysis are presented in three distance bins: 0.5, 1.0 and 1.5 n.miles. All sightings made beyond 1.5 n.miles were discarded.

\section{Spatial calculations}

A spherical method (Ersts et al., 2008) for computing perpendicular distances estimates was chosen in part because of the inability to use angle boards, but also because it could be directly used with the geographical coordinates (i.e. longitude and latitude) and standard compass bearings. This spherical method also generates the geographical coordinates of each sighting which can be used in other broad scale spatial analyses.

The geographic mean longitude and latitude of the minimum bounding rectangle for each transect was used to produce both an east-west and north-south subdivision. A coarse examination of distribution of sighting made during passing mode was undertaken by tallying the number of sightings in both the east-west and north-south subdivision for each of the three survey sites using all available sightings out to 1.5 n.miles from the transect. The latitudinal or longitudinal mean can be used to divide a rectangular region into two parts of equal area regardless of the north-south or east-west orientation of the rectangle. However, together, latitudinal and longitudinal means will only provide four subdivisions of equal area when the rectangular area has an exact north-south or east-west orientation.

\section{RESULTS}

\section{Humpback whale group composition}

Humpback whales were the only large whale species encountered during closing mode surveys in the GeyserZélée Complex and on Iris Bank (Table 3). A total of 56 groups of humpback whales were encountered. No competitive groups were encountered during closing mode, however, two competitive groups were observed during passing mode surveys on the Geyser-Zélée Complex in 2003. Acoustic watches were neither performed on a regular basis nor in a systematic fashion, thus the number of singers is likely to be negatively biased. Nonetheless, single whales were infrequently encountered. Mean group size was 1.96 for both the Geyser-Zélée Complex and Iris Bank ( $n=26$, $\mathrm{SD}=0.34$ and $n=30, \mathrm{SD}=0.49$ respectively).

Females with calves were the most frequently encountered group type on both the Geyser-Zélée Complex and Iris Bank (69.23\%, $n=18$ and $70.00 \%, n=21$ respectively). Pairs accounted for the second most frequently encountered group type on the Geyser-Zélée Complex and Iris Bank (23.08\%, $n=6$ and $16.66 \%, n=5$ respectively). Assuming an equal probability of encountering a pair, single animal, or female with a calf, the proportion of females with calves

Table 3

Number of encounters by species and humpback whale group type recorded during closing mode surveys on the GeyserZélée Complex and Iris Bank.

\begin{tabular}{|c|c|c|c|c|}
\hline & \multicolumn{2}{|c|}{ Geyser-Zélée Complex } & \multicolumn{2}{|c|}{ Iris Bank } \\
\hline & 2002 & 2003 & 2002 & 2003 \\
\hline Humpback whale & 17 & 9 & 13 & 17 \\
\hline Mother-calf & 11 & 6 & 6 & 12 \\
\hline Mother-calf-escort & 1 & - & - & 3 \\
\hline Pair & 4 & 2 & 4 & 1 \\
\hline Singleton & 1 & - & 2 & 1 \\
\hline Singer & - & 1 & 1 & - \\
\hline Spinner dolphin & 1 & 2 & 4 & 3 \\
\hline Pantropical spotted dolphin & - & - & - & 1 \\
\hline Spinner and pantropical spotted dolphin & 2 & 1 & 2 & 2 \\
\hline Indo-Pacific bottlenose dolphin & - & - & 1 & 1 \\
\hline Melon-headed whale & - & - & - & 1 \\
\hline
\end{tabular}


was significantly higher for the 2002 survey of the GeyserZélée Complex $\left(\chi_{2}^{2}=11.41, p<0.01\right)$, and the 2003 survey of Iris Bank $\left(\chi_{2}^{2}=23.06, p<0.001\right)$. There was no significant difference in the proportion of pairs, single animals, or females with calves encountered during the 2002 survey of Iris Bank $\left(\chi_{2}^{2}=1.07, p>0.5\right)$ nor for the 2003 survey of the Geyser-Zélée Complex $\left(\chi_{2}^{2}=4.66\right.$, $p>0.096)$. The sample size was too small to examine pairwise comparisons of group type frequency by year and location.

\section{Individually identified humpback whales}

A total of 26 humpback whales were identified over the course of these surveys using photographs of tail flukes (Table 2). Alternatively, 76 humpback whales were identified using photographs of dorsal fins from the left side of the animal. Whales that were only represented by photographs of dorsal fins from the right side were not included in this analysis. Individuals identified by dorsal fins are presented as an alternative expression for the number of individuals encountered because of the infrequency at which the animals encountered in this region have fluke-up dives (Ersts, pers. obs).

Encounter rates and sightings per unit of closing mode effort were higher for the Geyser-Zélée Complex than Iris Bank (Table 2). While there was a substantial decrease in group encounter rate and total closing mode effort between 2002 and 2003 on the Geyser-Zélée Complex, there was a slight increase in the rate of identified individuals per hour. Conversely, there was only a marginal increase in total closing mode effort between 2002 and 2003 on Iris Bank, but a noticeable increase in both the group encounter rate and rate of identification by dorsal fin.

With the exception of three mother-calf pairs, all individuals identified on the Geyser-Zélée Complex and Iris Bank were only encountered once. One mother-calf pair was encountered on three consecutive days in the interior of Geyser Reef during the 2002 survey. On Iris Bank, one mother-calf pair was observed twice during the 2002 surveys with four days between sightings. Two additional multi-day sighting of mother-calf pairs were recorded during the 2003 season (one with four days between consecutive sightings and the other with five days between consecutive sightings).

\section{Humpback whale density}

Since no other species of large whales were encountered during closing mode surveys and only two additional encounters with two other large species of cetacean (sperm whale [Physeter macrocephalus] and blue whale [Balaenoptera musculus]) have been documented for the waters surrounding Mayotte in recent years (Kiszka et al., 2007), all observations made during passing mode that were labelled as 'whale-like' were subsequently considered to be humpback whales and used in the estimation of whale density (Table 4). Of all humpback whale and 'whale like' sightings, blows were the most observed cue $(47 \%, n=63)$. Body and body parts (i.e. tail flukes, dorsal and pectoral fins) were the second most frequently observed cues $(29 \%, n=$ $39)$ and breaches accounted for $24 \%(n=32)$ of the observed cues.

Whale density was calculated by multiplying the group density by the mean group size of encounters recorded during closing mode surveys on Iris Bank and in the GeyserZélée Complex. Considerable variation was found among each passing mode survey (Table 4). Sightings from each transect were examined for differential distribution among the transect legs for each of the three strip widths using chisquared tests assuming an equal sighting probability on any given leg of the transect. With the exception of the 8 October survey, the distribution of sightings among transect legs did not significantly deviate from the expected frequencies for any transect and the deviation observed on the 8 October survey was only marginally significant $\left(\chi_{2}^{2}=14.45, p=\right.$ 0.044).

The close proximity of the transect legs caused observational overlap between adjacent legs; the amount of which is proportional to the strip width under consideration and to the survey vessels proximity to the start or end of any given leg. This overlap, in addition to the mobility of the animals under consideration, introduced the possibility that certain groups of animals may have been double counted, introducing a positive bias to the density estimation. The influence from these possible double captures was examined by independently calculating density estimates derived from non adjacent legs and comparing them to the density estimate derived from all legs, for each time the transect was surveyed using the Wilcoxon matched-pairs signed-ranks test. The null expectation would be that no difference should be observed

Table 4

Upper half of the table provides the frequency of number of sightings made during passing mode surveys on Geyser Reef, Zélée Bank and Iris Bank. Values in square brackets indicate the number of sightings within 0.5 n.mile, 1 n.mile, and $1.5 \mathrm{n}$. miles of the transect respectively. The lower half of the table provides the number of sighting within the indicated strip width and the resulting whale density is provided in parentheses.

\begin{tabular}{|c|c|c|c|c|c|c|c|c|}
\hline & \multicolumn{3}{|c|}{ Geyser Reef } & \multicolumn{3}{|c|}{ Zélée Bank } & \multicolumn{2}{|c|}{ Iris Bank } \\
\hline & $12 / 09 / 02$ & 06/10/03 & 07/10/03 & $13 / 09 / 02$ & $05 / 10 / 03$ & $08 / 10 / 03$ & $09 / 10 / 03$ & $10 / 10 / 03$ \\
\hline 'Whale-like' & $\begin{array}{c}4 \\
{[3,3,4]}\end{array}$ & $\begin{array}{c}4 \\
{[1,1,1]}\end{array}$ & $\begin{array}{c}8 \\
{[1,2,5]}\end{array}$ & $\begin{array}{c}3 \\
{[2,2,2]}\end{array}$ & $\begin{array}{c}8 \\
{[2,3,3]}\end{array}$ & $\begin{array}{c}17 \\
{[4,8,12]}\end{array}$ & $\begin{array}{c}3 \\
{[0,0,0]}\end{array}$ & $\begin{array}{c}0 \\
{[0,0,0]}\end{array}$ \\
\hline 'Dolphin-like' & & 1 & 1 & 2 & 3 & 1 & 2 & \\
\hline Stenella spp. & & & 1 & & & & 1 & \\
\hline Melon-headed whale & & & & & & & 1 & \\
\hline Transect distance (n.miles) & 36.53 & 36.6 & 36.79 & 34.75 & 35.31 & 35.38 & 36.54 & 36.55 \\
\hline Obs. to 0.5 n.mile (whale density) & $\begin{array}{c}21 \\
(1.129)\end{array}$ & $\begin{array}{c}8 \\
(0.429\end{array}$ & $\begin{array}{c}4 \\
(0.214)\end{array}$ & $\begin{array}{c}15 \\
(0.864)\end{array}$ & $\begin{array}{c}11 \\
(0.612)\end{array}$ & $\begin{array}{c}11 \\
(0.610)\end{array}$ & $\begin{array}{c}3 \\
(0.161)\end{array}$ & $\begin{array}{c}1 \\
(0.054)\end{array}$ \\
\hline Obs. to 1 n.mile (whale density) & $\begin{array}{c}23 \\
(0.618)\end{array}$ & $\begin{array}{c}10 \\
(0.268)\end{array}$ & $\begin{array}{c}7 \\
(0.187)\end{array}$ & $\begin{array}{c}17 \\
(0.479)\end{array}$ & $\begin{array}{c}16 \\
(0.445)\end{array}$ & $\begin{array}{c}16 \\
(0.444)\end{array}$ & $\begin{array}{c}4 \\
(0.107)\end{array}$ & $\begin{array}{c}1 \\
(0.027)\end{array}$ \\
\hline Obs. to 1.5 n.mile (whale density) & $\begin{array}{c}25 \\
(0.448)\end{array}$ & $\begin{array}{c}11 \\
(0.196)\end{array}$ & $\begin{array}{c}10 \\
(0.178)\end{array}$ & $\begin{array}{c}17 \\
(0.320)\end{array}$ & $\begin{array}{c}17 \\
(0.315)\end{array}$ & $\begin{array}{c}21 \\
(0.388)\end{array}$ & $\begin{array}{c}5 \\
(0.089)\end{array}$ & $\begin{array}{c}1 \\
(0.018)\end{array}$ \\
\hline
\end{tabular}


between the densities calculated from all legs compared to non-adjacent legs. For each survey, the density estimates derived using all legs of a transect were bounded on both sides by the density estimates derived using non-adjacent legs. Consequently, the results of the Wilcoxon matchedpairs signed-ranks test were the same for both density comparisons $(\mathrm{T}=125, n=24, p>0.48)$ and the null expectation was not rejected in either situation. Even though a positive bias was likely introduced, the density estimates generated here are not being used for population estimation where the implications would be an overestimate of population size.

\section{Humpback whale distribution}

Understanding of the Geyser-Zélée Complex was limited to general environmental descriptions (Quod et al., 2000; UNEP and IUCN, 1988) and coarse bathymetric data interpreted from nautical charts. It was assumed that the areas being surveyed were generally environmentally featureless relative to the size of a humpback whale. Therefore animals were expected to be evenly distributed. To broadly determine if distribution was uniform, sightings out to 1.5 n.miles were pooled for Iris Bank $(n=7)$, Geyser Reef $(n=46)$ and Zélée Bank $(n=55)$ then analysed with respect to the longitudinal and latitudinal mean for each of the three transects. Few sightings were made during passing mode surveys on Iris Bank, yet they were all made on the western half of the bank. On Geyser Reef, sightings (70.0\%) were found to be concentrated on the eastern half of the area surveyed without notable differences in north-south concentrations (52.2\% and $47.8 \%$ respectively). Sighting on Zélée Bank showed both a concentration on the eastern $(67 \%)$ and southern zones $(65 \%)$. While the orientation of the transect on Zélée Bank had a very slight northwestsoutheast orientation, sightings on this bank can be broadly interpreted as being concentrated in the southeastern quadrant of the area surveyed.

\section{Other species observed}

Spinner dolphins (Stenella longirostris) and Pantropic spotted dolphins ( $S$. attenuata) were the second most commonly observed species and were frequently encountered together in mixed groups (Table 3). Two groups of Indo-Pacific bottlenose dolphin (Tursiops aduncus) were encountered on the Iris Bank. A group of approximately 600 melon-headed whales (Peponocephala electra) was encountered on the eastern edge of Iris Bank on 27 September 2003 during closing mode surveys and a smaller group of 30-40 individuals was later observed on 9 October during one of the passing mode surveys. The sighting on 27 September is best described as a super-group, stretching well over a nautical mile, comprised of distinct subgroups containing 30 to 60 individuals.

\section{DISCUSSION}

The results from these short, exploratory surveys of the Geyser-Zélée Complex and the subsequent comparison to Iris Bank provide much needed data on humpback whale encounter rates and densities in Wintering sub-Region C2 (IWC, 2011; Rosenbaum et al., 2001). Overall, the results indicate that the eastern region of the Comoros Archipelago is an important area for humpback whales during the late austral winter months and that additional, more intensive systematic research is warranted. It is necessary to reiterate that during computations of animal densities, detection functions were not fitted to the observations and no attempt was made to correct for biases associated with weather, detection distance estimates, or observer experience. Consequently, calculations of population size were not attempted and the resulting observed densities should only be considered general estimates. Regardless of the limitations and any potential biases that may exist in the observed density calculations, these results provide muchneeded data on humpback whale distribution and encounters for a region in which no other data of this type are currently available.

\section{Whale density}

The densities of humpback whales, out to one nautical mile from the transect, ranged from 0.027 to 0.618 whales n.miles ${ }^{2}$ across the three survey areas (Table 4 ). As expected, whale density decreased with each subsequent distance bin $(0.5$, 1.0 and 1.5 n.miles) due to a decreasing detection probability with increasing distance from the trackline (Buckland et al., 2001). The close proximity of the legs of each transect and the mobility of the animals under consideration introduced the possibility that certain groups of animals may have been double counted. Given that the density estimate derived from all legs of a transect was bounded on both sides by the density estimates derived from non-adjacent legs, the density estimates reported may be considered the median estimates of observed animal density for each survey. While it is highly likely that instances of double counting occurred, it was not possible to definitively quantify the degree of double counting and no attempts were made to derive population estimates using these data.

The apparent decrease from 2002 and 2003 in observed densities on the Geyser-Zélée Complex can be largely attributed to seasonality. Both the 2002 and 2003 surveys were conducted during the latter portion of the migratory cycle, but the 2003 surveys were conducted almost a full month later than the 2002 surveys. The magnitude of variation observed within the 2003 surveys in the GeyserZélée Complex is interesting but not wholly unexpected. A medium sized commercial fishing vessel had been working in and around the Geyser-Zélée Complex several days prior to and during the 2003 surveys. Additionally, on 4 October 2003, two large charter boats departed Mayotte on route to Geyser Reef to film whales. Consequently, a total of four large boats $(>12 \mathrm{~m})$ and several smaller fishing boats $(<8 \mathrm{~m})$ were present in Geyser Reef within the survey area during the 6 October and 7 October surveys. In contrast, only a few small open boats were observed on Geyser Reef in 2002. No other boats were observed on Zélée Bank in 2002 or 2003. The co-occurrence of variation observed within the 2003 surveys in the Geyser-Zélée Complex and increase in boat traffic merits further investigation, but cannot be quantified from these data. Any potential displacement of humpback whales from these banks due to anthropogenic activities is a considerable conservation and management concern.

\section{Group composition and encounter rates}

During the closing mode component of these surveys a total of 56 groups of humpback whales were approached. Significantly more females with young were encountered than pairs or single animals. No groups with more than four whales were encountered and competitive behaviour was only observed from afar on two occasions during passing mode surveys. There was no a priori knowledge or expectation in the frequency each group type may be encountered, thus each group type encountered was 
considered to have an equally probability of being observed. Based on these data alone, the greater propensity of encountering females with young is attributed to the lateseason timing of these surveys.

With no prior knowledge of the degree to which humpback whales used the offshore banks and reef systems throughout $\mathrm{C} 2$, the encounter rates for the Geyser-Zélée Complex were higher than anticipated, especially given that the surveys were conducted during the end of migratory cycle. Both the densities and the encounter rates seem to indicate that there are greater concentrations of animals on the Geyser-Zélée Complex than are found on the Iris Bank. However, several factors regarding the encounter rates must be considered. The survey platform used during closing mode surveys on Geyser-Zélée Complex offered a much higher vantage point than the platform used on Iris Bank. This undoubtedly had a positive influence on the ability to locate animals. Secondly, these surveys were notably short and the resulting encounter rates could be greatly influenced by an especially good or poor day on the water. Finally, drawing upon previous survey experiences of Iris Bank, whales encountered on Iris Bank can be exceedingly evasive. This evasiveness can result in unidentified whales, negatively impacting encounter rates for identified individuals.

\section{Localised distribution}

Based on the limited bathymetric data available, the interior regions of the Geyser Reef and Zélée Bank appear to be relatively uniform. Therefore it was expected that the distribution of humpback whales in the interiors of the complex would therefore also be relatively uniform and the same was expected for Iris Bank. Uniform distribution, however, was not evident. Instead, the sighting localities derived from observations made during passing mode surveys were found to be concentrated in the western half of Iris Bank, the southeast corner of Zélée Bank and in the eastern half of Geyser Reef.

The apparent differential distribution observed cannot fully be explained with the data from these short surveys alone. Fine scale habitat-relationship models could not be built from sighting localities due to the lack of detailed bathymetric data and the possible geographic inaccuracies resulting from the estimated detection distances. These results can only highlight coarse patterns in geographic distribution. As these three survey sites are small and featureless relative to the size of humpback whales, future surveys should examine which, if any, factor has its greatest influence on distribution, e.g. physical environment, social organisation, proximity to other humpback whales or proximity to anthropogenic activity.

\section{Conservation and management concerns}

The Geyser-Zélée Complex is currently less impacted by human activities, such as fishing and nature-based tourism, than Iris Bank due to its relative inaccessibility. Polunin and Frazier (1974) were the first to qualitatively note that the Geyser-Zélée Complex showed little evidence of anthropogenic impact in the early 1970s. Quod et al. (2000) found that Geyser-Zélée Complex began to be regularly exploited by fisherman as early as 1989, a trend that continues today. As resources have become depleted in the waters immediate adjacent to Mayotte and neighbouring islands (e.g. Anjouan and Madagascar), subsistence fisherman undertake risky, multi-day voyages to the GeyserZélée Complex and similar near by banks aboard small
$(<8 \mathrm{~m})$, open boats. Furthermore, Mayotte is being heavily promoted as an underdeveloped tourist destination and the newest concern is that the Geyser-Zélée Complex will be targeted as an attractive new destination for multi-day diving, fishing and, to a lesser extent, whalewatching trips or as a stopover point for charters running between Mayotte and Madagascar.

While the relative isolation of the Geyser-Zélée Complex has afforded humpback whales and other marine mammals some degree of solitude in the past, the complex remains unmonitored and poorly understood. To date the governing administration has not adopted any official conservation or management policies concerning the Geyser-Zélée Complex even though recent trends in fishing and charter boat activity are increasing. Conversely, Iris Bank and the waters surrounding Mayotte are easily accessible to recreational boaters and whalewatching operators. Marine mammals are protected in the waters surrounding Mayotte, but enforcement and monitoring are largely insufficient due to lack of personnel and poor communication between departments within the administration.

Currently, there are no applicable estimates of the direct energetic costs to humpback whales associated with displacement (Baker and Herman, 1989) or demonstrations of permanent, large-scale population-level effects (Corkeron, 2004) associated with vessel traffic. Given the group types observed in the survey areas, their proximity to human activity and time-scales for which any chronic and largescale population-level effects are likely to be measured (Bejder et al., 2006), a precautionary management approach (Robinson, 2006) is recommended in the absence of these data. Collection of adequate baseline data should be initiated to monitor trends through time and this effort should start before there are significant increases in nature based tourism or in the promotion of nature based tourism.

\section{CONCLUSION}

These results, while exploratory, indicate that humpback whales are found in varying concentrations in offshore reef systems and on banks in Wintering sub-Region C2. Generally, the marine mammals in the waters of Mayotte and the Geyser-Zélée Complex remain poorly understood and face a potential increasing exposure to anthropogenic noise and disturbance from human activities. The conservation and management challenges Mayotte and the Geyser-Zélée Complex face are not unique in the sense that they face many of same threats and pressures as other marine environments around the world. These initial results will hopefully serve as a catalyst for further research and highlight the potential of this largely under-studied region. At the 2006 Workshop on the Comprehensive Assessment of Southern Hemisphere Humpback Whales convened in Hobart, Australia, it was recommended that efforts be made to undertake more extensive ship-based surveys throughout Wintering Region C (IWC, 2011). The collection of adequate data with the ability to discern temporal differences will require a considerable resource commitment and highlights the need for better international and regional cooperation.

\section{ACKNOWLEDGEMENTS}

We thank the FFEM and the Collectivité Départementale de Mayotte for funding this research and La Direction de l'Agriculture et de la Forêt and Service de la Pêche et de l'Environnement Marin for logistical support and the use of 
their facilities and equipment. We would like to thank Olivier Abellard, Nicolas Maslach, Marilyn Journet, Gianna and Keith Minton, Ibrahim Amhed, Sonia Ribes-Beaudemoulin, Julien Wickel, Frank Charlier, Ahmed Djanfar, Jaco Barendse for their participation in these surveys and Didier Desmaison and the other crew of the Turquoise. Peter Best and an anonymous reviewer provided valuable feedback that help strengthen this manuscript.

\section{REFERENCES}

Baker, C.S. and Herman, L.M. 1981. Migration and local movement of humpback whales (Megaptera novaeangliae) through Hawaiian waters. Can. J. Zool. 59: 460-69.

Baker, C.S. and Herman, L.M. 1984. Aggressive behavior between humpback whales (Megaptera novaeangliae) wintering in Hawaiian waters. Can. J. Zool. 62: 1922-37.

Baker, C.S. and Herman, L.M. 1989. Behavioural responses of summering humpback whales to vessel traffic. Experimental and opportunistic observations. Report NPS-NR-TRS-89-01 to the US National Park Service, Anchorage, AK. [Available from Glacier Bay National Park, PO Box 140, Gustavus, Alaska 99826]. 50pp.

Baker, C.S., Herman, L.M., Perry, A., Lawton, W.S., Straley, J.M., Wolman, A.A., Kaufman, G.D., Winn, H.E., Hall, J.D., Reinke, J.M. and Ostman, J. 1986. Migratory movement and population structure of humpback whales, Megaptera novaeangliae, in the central and eastern North Pacific. Mar. Ecol. Prog. Ser. 31: 105-19.

Balcomb, K.C. and Nichols, G. 1982. Humpback whale censuses in the West Indies. Rep. int. Whal. Commn 32: 401-06.

Bejder, L., Samuels, A., Whitehead, H., Gales, N., Mann, J., Connor, R., Heithaus, M., Watson-Capps, J. and Flaherty, C. 2006. Decline in relative abundance of bottlenose dolphins exposed to long-term disturbance. Conserv. Biol. 20(6): 1,791-798.

Best, P.B., Findlay, K.P., Sekiguchi, K., Peddemors, V.M., Rakotonirina, B., Rossouw, A. and Gove, D. 1998. Winter distribution and possible migration routes of humpback whales Megaptera novaeangliae in the southwest Indian Ocean. Mar. Ecol. Prog. Ser. 152: 287-99.

Best, P.B., Sekiguchi, K., Rakotonirina, B. and Rossouw, A. 1996. The distribution and abundance of humpback whales off southern Madagascar, August-September 1994. Rep. int. Whal. Commn 46: 32331.

Blackmer, A.L., Anderson, S.K. and Weinrich, M.T. 2000. Temporal variability in features used to photo-identify humpback whales (Megaptera novaeangliae). Mar. Mammal Sci. 16(2): 338-54.

Buckland, S.T., Anderson, D.R., Burnham, K.P., Laake, J.L., Borchers, D.L. and Thomas, L. 2001. Introduction to Distance Sampling: Estimating Abundance of Biological Populations. Oxford University Press, Oxford, UK. vi+xv+432pp.

Calambokidis, J., Steiger, G.H., Straley, J., Herman, L.M., Cerchio, S., Salden, D., Urbán R, J., Jacobsen, J.K., von Zeigesar, O., Balcomb, K.C., Gabriele, C.M., Dahlheim, M.E., Uchida, S., Ellis, G., Miyamura, Y., Ladrón de Guevara P, P., Yamaguchi, M., Sato, F., Mizroch, S.A., Schlender, L., Rasmussen, K. and Barlow, J. 2001. Movements and population structure of humpback whales in the North Pacific. Mar. Mammal Sci. 17(4): 769-94.

Cerchio, S., Gabriele, C.M., Norris, T.F. and Herman, L.M. 1998. Movements of humpback whales between Kauai and Hawaii: implications for population structure and abundance estimation in the Hawaiian Islands. Mar. Ecol. Prog. Ser. 175: 13-22.

Clapham, P.J., Palsbøll, P.J., Mattila, D.K. and Vasquez, O. 1992. Composition and dynamics of humpback whale competitive groups in the West-Indies. Behaviour 122(Part 3-4): 182-94.

Corkeron, P.J. 2004. Whale watching, iconography and marine conservation. Conserv. Biol. 18(3): 847-49.

Darling, J.D. and Morowitz, H. 1986. Census of 'Hawaiian' humpback whales (Megaptera novaeangliae) by individual identification. Can. J. Zool. 64: 105-11.

Dawbin, W.H. 1966. The seasonal migratory cycle of humpback whales. pp.145-70. In: Norris, K.S. (eds). Whales, Dolphins, and Porpoises University of California Press, Berkeley and Los Angeles. $\mathrm{xv}+789 \mathrm{pp}$.

Ersts, P.J., Horning, N. and Polin, M. 2008. Perpendicular distance calculator (version 1.2.2) documentation. American Museum of Natural History, Center for Biodiversity and Conservation. [Available from http://biodiversityinformatics.amnh.org/open_source/pdc].

Ersts, P.J. and Rosenbaum, H.C. 2003. Habitat preference reflects social organization of humpback whales (Megaptera novaeangliae) on a wintering ground. J. Zool., London. 260: 337-45.
Ersts, P.J., Pomilla, C., Kiszka, J., Cerchio, S., Rosenbaum, H.C., Vély, M., Razafindrakoto, Y., Loo, J.A., Leslie, M.S. and Avolio, M. 2011. Observations of individual humpback whales utilising multiple migratory destinations in the south-western Indian Ocean. Afr. J. Mar. Sci. 33(2): 333-38.

Findlay, K.P. and Best, P.B. 1996. Assessment of heterogeneity in sighting probabilities of humpback whales within viewing range of Cape Vidal, South Africa. Mar. Mammal Sci. 12(3): 335-53.

Findlay, K.P., Best, P.B., Peddemors, V.M. and Gove, D. 1994. The distribution and abundance of humpback whales on their southern and central Mozambique winter grounds. Rep. int. Whal. Commn 44: 311-20.

Garrigue, C., Aguayo, A., Amante-Helwig, V.L.U., Baker, C.S., Caballero, P., Clapham, P., Constantine, R., Denkinger, J., Donoghue, M., FlorezGonzalez, L., Greaves, J., Hauser, N., Olavarria, C., Pairoa, C., Peckham, H. and Poole, M. 2002. Movements of humpback whales in Oceania, South Pacific. J. Cetacean Res. Manage. 4(3): 255-60.

Garrigue, C., Forestell, P., Greaves, J., Gill, P., Naessig, P. and Baker, C.S. 2000. Migratory movement of humpback whales (Megaptera novaeangliae) between New Caledonia, East Australia and New Zealand. J. Cetacean Res. Manage. 2(2): 101-10.

International Whaling Commission. 2000. Report of the Scientific Committee. Annex G. Report of the sub-committee on the Comprehensive Assessment of other whale stocks. J. Cetacean Res. Manage. (Suppl.) 2:167-208.

International Whaling Commission. 2004. Report of the Scientific Committee. Annex H. Report of the Sub-Committee on Other Southern Hemisphere Whale Stocks. Appendix 7. Report of the intersessional working group: work required to complete assessment of southern hemisphere humpback whales. J. Cetacean Res. Manage. (Suppl.) 6:25967.

International Whaling Commission. 2011. Report of the Workshop on the Comprehensive Assessment of Southern Hemisphere humpback whales, 4-7 April 2006, Hobart, Tasmania. J. Cetacean Res. Manage. (special issue 3): $1-50$.

Katona, S.K. and Whitehead, H.P. 1981. Identifying humpback whales using their natural markings. Polar Rec. 20: 439-44.

Kiszka, J., Ersts, P.J. and Ridoux, V. 2007. Cetacean diversity around the Mozambique Channel island of Mayotte (Comoros Archipelago). J. Cetacean Res. Manage 9(2): 105-10.

Mate, B.R., Gisiner, R. and Mobley, J. 1998. Local and migratory movements of Hawaiian humpback whales tracked by satellite telemetry. Can. J. Zool. 76: 863-68.

Mattila, D.K. and Clapham, P.J. 1989. Humpback whales, Megaptera novaeangliae, and other cetaceans on Virgin Bank and in the northern Leeward Islands, 1985 and 1986. Can. J. Zool. 67(9): 2201-11.

Mattila, D.K., Clapham, P.J., Katona, S.K. and Stone, G.S. 1989. Population composition of humpback whales, Megaptera novaeangliae, on Silver Bank, 1984. Can. J. Zool. 67: 281-85. [Abstract also in French].

Mattila, D.K., Clapham, P.J., Vásquez, O. and Bowman, R.S. 1994. Occurrence, population composition, and habitat use of humpback whales in Samana Bay, Dominican Republic. Can. J. Zool. 72(11): 1898-907.

Polunin, N.V.C. and Frazier, J.G. 1974. Diving reconnaissance of twenty seven western Indian Ocean coral reefs. Environ. Conserv. 1(1): 71-72.

Quod, J.P., Naim, O. and Abdourazi, F. 2000. The Comoros archipelago. pp.243-52. In: Sheppard, C. (eds). Seas at the Millennium: An Environmental Evaluation. Pergamon Press, Oxford.

Robinson, J.G. 2006. Conservation biology and real-world conservation. Conserv. Biol. 20(3): 658-59.

Rosenbaum, H.C., Ersts, P. and Findlay, K. 2001. Regional planning workshop on collaborative research and conservation of humpback whales in the Indian and South Atlantic Oceans. Paper SC/53/IA23 presented to the IWC Scientific Committee, July 2001, London (unpublished). 16pp. [Paper available from the Office of this Journal].

Rosenbaum, H.C., Walsh, P.D., Razafindrakoto, Y., Vely, M. and DeSalle, R. 1997. First description of a humpback whale breeding ground in Baie d'Antongil, Madagascar. Conserv. Biol. 11(2): 312-4.

Smultea, M.A. 1994. Segregation by humpback whale (Megaptera novaeangliae) cows with a calf in coastal habitat near the island of Hawaii. Can. J. Zool. 72(5): 805-11.

Tyack, P. and Whitehead, H. 1983. Male competition in large groups of wintering humpback whales. Behaviour 83: 132-54.

UNEP and IUCN. 1988. Coral Reefs of the World. Volume 3. Central and West Pacific. IUCN, Gland, Switzerland and Cambridge, UK, UNEP, Nairobi, Kenya. 329pp.

Urban, J. and Aguayo, A. 1987. Spatial and seasonal distribution of the humpback whale, Megaptera novaeangliae, in the Mexican Pacific. Mar. Mammal Sci. 3(4): 333-44.

Whitehead, H. and Moore, M.J. 1982. Distribution and movements of West Indian humpback whales in winter. Can. J. Zool. 60: 2203-11. 